\title{
Correction to: A Model-Informed Method for the Purpose of Precision Dosing of Isoniazid in Pulmonary Tuberculosis
}

\author{
Stijn W. van Beek ${ }^{1} \oplus \cdot$ Rob ter Heine $^{1} \cdot$ Jan-Willem C. Alffenaar ${ }^{2,3,4} \cdot$ Cecile Magis-Escurra $^{5} \cdot$ Rob E. Aarnoutse $^{1}$. \\ Elin M. Svensson ${ }^{1,6}$ on behalf of the Isoniazid Precision Dosing Group
}

Published online: 3 April 2021

(c) The Author(s) 2021

\section{Correction to: Clinical Pharmacokinetics https://doi.org/10.1007/s40262-020-00971-2}

The original text states that all volume and clearance parameters were allometrically scaled based on total body weight and that allometric scaling based on fat-free mass was not considered as height is not always readily available in TDM practice. During model development, we decided that height can easily be collected and allometric scaling based on fatfree mass should be considered. Allometric scaling based on fat-free mass was significantly better than scaling based on total body weight and was included in the final model. All volume and clearance parameters listed in Table 2 are applicable for a patient with a fat-free mass of $45 \mathrm{~kg}$.

This error affects the text in three places:

1. In the methods section under 'Pharmacokinetic Model Development', first paragraph: 'All volume and clearance parameters were allometrically scaled with total body weight

The original article can be found online at https://doi.org/10.1007/ s40262-020-00971-2.

Stijn W. van Beek

Stijn.vanBeek@radboudumc.nl

1 Department of Pharmacy, Radboud Institute for Health Sciences, Radboud University Medical Center, Geert Grooteplein zuid 10, 864, 6500 HB, Nijmegen, The Netherlands

2 School of Pharmacy, Faculty of Medicine and Health, University of Sydney, Sydney, NSW, Australia

3 Westmead Hospital, Sydney, NSW, Australia

4 Marie Bashir Institute of Infectious Diseases and Biosecurity, University of Sydney, Sydney, NSW, Australia

5 Department of Respiratory Diseases, Radboud University Medical Center, Nijmegen, The Netherlands

6 Department of Pharmacy, Uppsala University, Uppsala, Sweden using an exponent of 1 or 0.75 , respectively [35]. Allometric scaling based on fat-free mass was not considered because height is not always readily available in TDM practice.'

Correct text:

'All volume and clearance parameters were allometrically scaled with fat-free mass using an exponent of 1 or 0.75 , respectively [35]. Fat-free mass was computed as described previously [Janmahasatian S, Duffull SB, Ash S, et al. Quantification of lean bodyweight. Clin Pharmacokinet. 2005;44(10):1051-65.].'

2. In the methods section under 'Pharmacokinetic Model Development', third paragraph: 'It was opted to include only the allometric scaling with total body weight to not hamper a general implementation of the model in routine TDM.'

This sentence should be removed.

3. In the results section under 'Pharmacokinetic Model', first paragraph: 'The volume of the liver compartment and hepatic plasma flow were fixed to $1 \mathrm{~L}$ and $49.5 \mathrm{~L} / \mathrm{h}$, respectively, and allometrically scaled on total body weight like other volume and clearance parameters.'

Correct text:

'The volume of the liver compartment and hepatic plasma flow were fixed to $1 \mathrm{~L}$ and $49.5 \mathrm{~L} / \mathrm{h}$, respectively, and allometrically scaled on fat-free mass (reference 45 $\mathrm{kg}$ ) like other volume and clearance parameters.'

Open Access This article is licensed under a Creative Commons Attribution-NonCommercial 4.0 International License, which permits any non-commercial use, sharing, adaptation, distribution and reproduction in any medium or format, as long as you give appropriate credit to the original author(s) and the source, provide a link to the Creative Commons licence, and indicate if changes were made. The images or other third party material in this article are included in the article's Creative Commons licence, unless indicated otherwise in a credit line to the material. If material is not included in the article's Creative Commons licence and your intended use is not permitted by statutory regulation or exceeds the permitted use, you will need to obtain permission directly from the copyright holder. To view a copy of this licence, visit $\mathrm{http} / / /$ creativecommons.org/licenses/by-nc/4.0/. 